\title{
POLÍTICA EXTERNA BRASILEIRA E OS BLOCOS INTERNACIONAIS
}

Flavia de Campos Mello

\begin{abstract}
Resumo: A análise do quadro atual das relações exteriores do Brasil, com respeito ao Mercosul e às negociações da Alca, exige também uma avaliação histórica. Nesse sentido deve-se recuperar as origens e a evolução das estratégias regionalistas da política externa brasileira na década de 90 .

Palavras-chave: política externa brasileira; Mercosul; Alca.

Abstract: An analysis of the current state of Brazil's foreign policy relations with regard to Mercosul and FTAA negotiations requires a historical perspective, including an examination of the regional strategies of Brazil's foreign policy during the 1990's.

Key words: Brazilian foreign policy; Mercosul; FTAA.
\end{abstract}

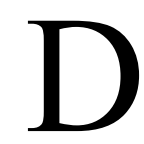
esde o final do ano 2000, a política externa brasileira enfrenta dificuldades na articulação das estratégias diplomáticas do País nos planos subregional (Mercosul), regional (América do Sul), hemisférico (Alca) e inter-regional (as negociações MercosulUnião Européia). Num contexto no qual se acentuaram as inter-relações entre esses diversos planos, foram explicitados os condicionamentos e limites das estratégias regionalistas traçadas pela política externa brasileira da última década. Este artigo recupera as origens dessas diretrizes e sua evolução desde o início dos anos 90 para analisar o quadro atual das relações externas do Brasil quanto ao Mercosul e às negociações da Alca. ${ }^{1}$

\section{ORIGENS: O MERCOSUL E O PLANO BUSH}

Constata-se hoje que as estratégias regionalistas da política externa brasileira que foram definidas no início da década de 90, no contexto da gênese do Mercosul, em paralelo com as negociações para a criação do Nafta e com o lançamento da Iniciativa para as Américas do presidente George Bush, mantiveram-se praticamente inalteradas desde então. Em 1990, a retomada e o novo formato da integração bilateral Brasil-Argentina, iniciada nos governos Sarney e Alfonsín, refletiam a convergência política entre os governos Collor e Menem, que buscaram vincular suas políticas externas à reestruturação e às reformas econômicas domésticas. Ao mesmo tempo, constituíram uma resposta defensiva aos impactos potenciais de outros processos de regionalização e, sobretudo, antecipavam possíveis efeitos que adviriam da formação do Nafta. Ante o anúncio do Plano Bush, em junho de 1990, que propunha pela primeira vez a criação de uma área de livre-comércio hemisférica, a estratégia da diplomacia brasileira consistiu em articular uma resposta conjunta com a Argentina, o Chile e o Uruguai, destacando que a iniciativa norte-americana não poderia contrapor-se aos esquemas de integração em curso no Cone Sul nem cercear as opções de cooperação com outras regiões do mundo. Essa articulação viria a constituir a origem do Mercosul, ao evidenciar que o Chile não iria aderir ao arranjo sub-regional e ao incorporar o Uruguai e posteriormente o Paraguai. Além do alargamento da integração sub-regional com a adesão dos dois novos sócios, o anúncio do Plano Bush também incidiu sobre a opção pelo aprofundamento do projeto do Mercosul, que 
teria por meta não apenas a criação de uma área de livrecomércio, mas também a constituição de um mercado comum, com tarifa externa comum e atuação conjunta de seus membros em negociações externas.

Desde então, o Brasil foi o único país da América Latina que, de alguma forma, resistiu a todas as iniciativas dos Estados Unidos para a região, mantendo os mesmos objetivos estabelecidos em 1990: assegurar a atuação conjunta do Mercosul para fortalecer seu poder de barganha nas negociações com Washington; evitar a defecção da Argentina; tentar alterar a natureza unilateral da proposta norte-americana; e impedir que o bloco sub-regional pudesse vir a ser diluído caso a área de livre-comércio hemisférica fosse de modo efetivo deslanchada (Lima, 1996:149; Magalhães, 1999:83). Ao longo da década de 90, todas as sinalizações dos Estados Unidos com a finalidade de avançar na integração hemisférica resultaram no fortalecimento do compromisso brasileiro com o aprofundamento e/ou o alargamento da integração sub-regional (Albuquerque, 1998; Lima, 1999).

No próprio momento de gestação do projeto do Mercosul, já era explícita a divergência de posições entre Brasil e Argentina acerca dos objetivos do processo de integração sub-regional. Quando da assinatura da Ata de Buenos Aires e da decisão de cooordenar posições perante o Plano Bush, em 1990, o discurso argentino referia-se à “unidade continental”, entendendo o Mercosul como um primeiro passo na integração continental, enquanto o Brasil já enfatizava que sua prioridade consistiria no fortalecimento da unidade sub-regional para mais tarde tornar possível uma eventual negociação hemisférica.

De fato, o formato e a evolução posterior do processo de integração sub-regional instaurado em 1990 demonstraram que, embora os marcos gerais do projeto inicial de política externa do governo Collor estivessem voltados para a aproximação e a convergência com as posições dos Estados Unidos, a diplomacia brasileira encontrou no Mercosul um espaço para uma atuação internacional independente do eixo central nas relações com Washington. Da perspectiva da diplomacia brasileira, a união aduaneira do Mercosul não apenas fortaleceria o poder de barganha do Brasil nas negociações hemisféricas, mas também poderia constituir uma plataforma para um projeto de inserção global, autônoma, colocando o País no mapa dos blocos internacionais. ${ }^{2}$ Análises da política externa brasileira nesse período já salientavam que a consolidação da estratégia regionalista do Brasil decorreu, em parte, da "necessidade do Ministério das
Relações Exteriores de criar um campo de intervenção ativa", no qual "a diplomacia consegue notável poder decisório de formulação e implementação, na linha da busca de uma ação de política internacional de autonomia" (Vigevani e Veiga, 1991:45).

Essas diretrizes foram posteriormente explicitadas, na fase final do governo Collor, quando o discurso diplomático brasileiro passou a centrar-se na autodenominação do País como global trader, sintetizando a idéia de que, à diferença do México e do Canadá, o Brasil tem interesses diversificados e, portanto, não deveria proceder a adesões excludentes. Dada a estrutura diversificada de sua pauta de exportação (com destaque para o fato de que o comércio com a Comunidade Econômica Européia, no início da década de 90, ultrapassava bastante o comércio com os Estados Unidos), não interessaria ao Brasil vincular-se a um único parceiro ou bloco. Para um global trader, seria essencial a diversificação de opções, em estratégia internacional de várias frentes.

\section{EXPANSÃO NA AMÉRICA DO SUL}

Com a conclusão das negociações do Nafta ao final de 1992, as perspectivas de relacionamento dos Estados Unidos com a América Latina passariam também a contemplar a possibilidade de que o novo bloco incorporasse outros membros entre os países da região, para a qual os primeiros candidatos seriam o Chile e talvez a Argentina. Nesse momento, o Brasil foi caracterizado como o caso desviante, pelo atraso na estabilização monetária e na implementação das reformas econômicas, e por ser o único país a demonstrar um desinteresse explícito com relação também a essa segunda possibilidade nas iniciativas dos Estados Unidos para a região.

Além da prioridade conferida à conformação do Mercosul, a diplomacia brasileira deu então início à expansão de sua estratégia regionalista, buscando, na América do Sul, alternativas ao regionalismo liderado pelos Estados Unidos. Em dezembro de 1992, o Brasil anunciou o lançamento da Iniciativa Amazônica, que visava a negociação de acordos de complementação econômica com os países-membros do Tratado de Cooperação Amazônica (Bolívia, Equador, Colômbia, Venezuela, Peru, Suriname e Guiana). No ano seguinte, absorvendo a proposta da Iniciativa Amazônica, o Brasil lançou o projeto de criação de uma Área de Livre Comércio Sul-Americana (Alcsa), que visava congregar os países do Mercosul, do Grupo Andino e o Chile, mediante a negociação de uma 
rede de acordos de livre-comércio. À época, por ter sido apresentada aos países da região sem que os sócios do Mercosul fossem previamente consultados, a proposta da Alcsa gerou reações contrárias entre os vizinhos do Brasil no Cone Sul (Veiga, 1995:24). Embora tenha sido finalmente aceita pelo Mercosul, o unilateralismo da iniciativa brasileira já demonstrava que a nova prioridade conferida ao objetivo da expansão de suas relações com a América do Sul colocaria em segundo plano o objetivo de garantir a coesão do agrupamento sub-regional já formado. Conforme seria outra vez demonstrado nos últimos anos da década de 90 , o objetivo do alargamento da integração regional eventualmente assumiria prioridade com relação ao aprofundamento da integração sub-regional. Embora a Alcsa não tenha avançado sob o formato proposto de início, a estratégia regionalista brasileira na América do Sul seria fortalecida com o interesse da Bolívia e, em especial, do Chile em se associarem ao Mercosul, no contexto das dificuldades norte-americanas em promover a incorporação de novos membros no Nafta.

Também nesse período, a gestão de Fernando Henrique Cardoso no Itamaraty deu início à substituição do termo "América Latina" pelo "América do Sul" no discurso diplomático brasileiro, no qual excluía explicitamente o México e qualquer relação de proximidade com o Nafta, delimitando a nova esfera geográfica da estratégia regionalista brasileira. Na política externa do governo Itamar Franco, a nova prioridade conferida à América do Sul seria também articulada com o objetivo de promover uma atuação internacional protagônica para o Brasil nos foros multilaterais, em particular no contexto da perspectiva de ampliação do Conselho de Segurança da ONU. A idéia do Brasil como global trader foi então ampliada para a de global player, ao qual não caberia confinar suas relações econômicas e políticas a um único parceiro ou bloco.

\section{LANÇAMENTO DAS NEGOCIAÇÕES DA ALCA}

No ano de 1994, a preparação para a entrada em vigor da união aduaneira do Mercosul, o interesse de outros países da região em se associarem e a proposta de criação da Alcsa conformavam, com o diálogo inter-regional entre Mercosul e União Européia, as opções abertas para o regionalismo brasileiro. Demonstrando novamente as interrelações entre os processos sub-regional, regional, interregional e hemisférico, essas opções da política externa brasileira foram ainda reforçadas, nesse momento, pela convocação da Cúpula das Américas por parte do gover- no norte-americano, que viria a instaurar o processo de criação da Área de Livre Comércio das Américas.

Nas negociações do Mercosul, a nova iniciativa dos Estados Unidos gerou maior disposição da diplomacia brasileira a fazer concessões aos seus parceiros, para que fosse cumprido o objetivo de criar a união aduaneira até o final de 1994 - em paralelo com o interesse da área econômica do governo em antecipar a redução tarifária e a entrada em vigor da tarifa externa comum, determinado pela conjuntura do programa de estabilização. A Argentina, em particular, mantinha suas preferências por uma integração de alcance mais limitado, de todo explicitadas no contexto das dificuldades para alcançar a união aduaneira e das perspectivas de que o país pudesse tornar-se membro do Nafta. Em fevereiro de 1994, o ministro da economia, Domingo Cavallo, ainda declarava que, caso o Mercosul se restringisse "à meta mais realista de uma zona de livrecomércio, dadas as dificuldades dos acertos pendentes para a conformação da união aduaneira", a Argentina estaria livre e em condições de examinar individualmente eventual acordo de livre-comércio com os Estados Unidos (Magalhães, 1999:51).

Nas relações entre Mercosul e União Européia, a aproximação iniciou-se em 1992, como resultado da iniciativa e do empenho da diplomacia brasileira em fortalecer a atuação do Mercosul como ator internacional. Em dezembro de 1994, logo após a Cúpula das Américas lançar as bases da integração hemisférica, a União Européia propôs ao Mercosul a negociação de um acordo que aprofundasse as relações bi-regionais, um passo que sem dúvida resultava de uma resposta européia às possibilidades de formação da Alca. O acordo-quadro foi firmado em 1995, e o início das negociações para a liberalização comercial foi finalmente formalizado em 1999.

Também em 1994, no entanto, o Brasil aceitou com relutância a proposta norte-americana de iniciar as negociações para a criação da Alca, com base na avaliação de que, caso optasse por obstruir o processo, encontrar-se-ia em posição isolada no continente em confronto direto com os Estados Unidos (Lima, 1999). Nas negociações que precederam a Cúpula das Américas, o Brasil foi o principal defensor da opção por um prazo de dez anos para a conclusão das negociações, que prevaleceu na definição da data de 2005, enquanto a Argentina propunha que as negociações fossem concluídas até 2000 .

Após terem sido formalmente instauradas as negociações para a criação da Alca, a estratégia brasileira consistiu essencialmente em adiar ao máximo o início efetivo 
tanto das negociações substantivas quanto dos prazos para a liberalização. Adicionalmente, o Brasil buscou fortalecer sua posição de barganha em relação aos Estados Unidos, tentando, de um lado, angariar o apoio de outros países participantes das negociações, e, de outro lado, alterar a estrutura do processo negociador, mantendo os mesmos objetivos estabelecidos no contexto do Plano Bush, em 1990.

\section{APROFUNDAMENTO x ALARGAMENTO}

Com o avanço do processo negociador hemisférico a partir de 1995, o objetivo de construir alianças para fortalecer o poder de barganha brasileiro na Alca foi direcionado, em especial, para a estratégia de alargamento na América do Sul, iniciada com os acordos de associação do Chile e da Bolívia ao Mercosul, firmados em 1996. Embora os textos acordados na reunião ministerial da Alca de 1997 tivessem suscitado preocupações quanto à sobrevivência do Mercosul como agrupamento sub-regional quando a Alca entrar em vigor, a agenda de consolidação interna do bloco pouco avançou. Contudo, o Brasil obteve então o compromisso do Chile e da Bolívia de que coordenariam suas posições com o Mercosul nas negociações da Alca.

Na prática, após a passagem para a fase de união aduaneira, a integração no Mercosul permaneceu, de forma geral, estacionada em um mesmo patamar, marcada por dificuldades crescentes para avançar no processo de aprofundamento e por atritos constantes entre seus membros. O primeiro fator que incidiu na configuração desse novo contexto foi a própria complexidade de sua agenda, superada a fase de eliminação automática das tarifas intrabloco. Adicionalmente, a nova assimetria nas orientações da política econômica de seus principais membros acarretou uma menor inclinação para assumirem compromissos que restringissem sua capacidade de adotar decisões unilaterais. Suas implicações foram ainda agravadas pelo contexto de fragilidade macroeconômica e vulnerabilidade externa prevalecente na região, e exacerbadas pela instabilidade nos mercados financeiros internacionais em 1997 e 1998. A opção foi pela manutenção da flexibilidade na condução das políticas macroeconômicas, que freqüentemente agravou as situações de atrito entre seus membros. Nesse contexto, o acúmulo de descumprimentos aos acordos e de assuntos não resolvidos no aprofundamento da integração ampliou a agenda conflituosa e tendeu a reduzir as percepções acerca dos custos de cada nova medida unilateral.
Em particular, no período que se iniciou em 1995, a simultaneidade entre a passagem do Mercosul para a etapa de união aduaneira e a reorientação das políticas industriais e de comércio exterior brasileiras explicitou a relação existente entre a posição negociadora do Brasil e a dinâmica dos avanços na integração sub-regional. Diversas análises sobre a evolução da integração sub-regional na segunda metade da década de 90 coincidiram em diagnosticar a ausência de iniciativa do Brasil no aprofundamento do processo. Segundo Veiga, por exemplo, a posição brasileira foi o principal fator explicativo para os resultados limitados do Mercosul, a imperfeição de sua união aduaneira, seus reduzidos mecanismos de institucionalização, as poucas discriminações positivas em benefício dos dois parceiros menores e a ausência de avanços na agenda de consolidação e aprofundamento da integração (Veiga, 1999:25).

Na definição dessa posição, no entanto, a autonomia do Ministério das Relações Exteriores foi limitada. Em primeiro lugar, essa posição refletiu a prioridade atribuída pelo governo aos objetivos da estabilização macroeconômica. Em segundo lugar, a reorientação das políticas industriais e de comércio exterior do Brasil bem como a própria complexidade envolvida na nova etapa da integração do Mercosul conferiram um papel mais ativo ao Ministério da Indústria, do Comércio e do Turismo nas negociações externas. Quando as posições dos dois ministérios convergiram, como foi o caso com relação à Alca, a influência e o poder de barganha do Itamaraty no processo decisório foram fortalecidos. Nas relações comerciais com os parceiros do Mercosul, no entanto, a diplomacia brasileira não teve condições de impedir a adoção de medidas unilaterais (Lima, 1999).

Contudo, além dos fatores econômicos que fundamentaram a resistência brasileira ao aprofundamento da integração sub-regional, a avaliação quanto à incerteza que a ausência do fast track gerava para as perspectivas de avanço da Alca também constituiu um determinante significativo, de natureza diplomática, para a redução da prioridade conferida pelo Itamaraty à obtenção de avanços rápidos e abrangentes no Mercosul (Bouzas, 1999:15). Dessa forma, reverteram-se os incentivos que, em 1990 e em 1994, haviam resultado na convergência entre as prioridades das autoridades econômicas e os objetivos do Ministério das Relações Exteriores a fim de acelerar a integração subregional ante as perspectivas da integração hemisférica. Na avaliação da diplomacia brasileira em 1997, a ausência do fast track reduziria a pressão que o Executivo nor- 
te-americano estaria em condições de exercer sobre o processo, e, portanto, também reduziria os riscos de "diluição" do Mercosul no contexto da negociação da Alca, pelo menos em curto prazo.

Conforme já mencionado, após o documento final da III Reunião Ministerial da Alca ter incorporado, em maio de 1997, uma formulação dúbia acerca da coexistência dos arranjos sub-regionais com a integração hemisférica, o tema da possível diluição do Mercosul gerou preocupações quanto à necessidade do aprofundamento para garantir sua própria sobrevivência como bloco. Para manter sua identidade no contexto da zona de livre-comércio hemisférica, a integração do Mercosul precisaria avançar além dos compromissos previstos na agenda da Alca. No âmbito desse debate, no entanto, a reunião do Conselho do Mercosul de julho de 1997 evidenciou a existência de propostas e motivações distintas no que se referia às estratégias de seus membros para o aprofundamento da integração sub-regional. Para o Brasil, tratava-se de avançar na consolidação dos resultados já alcançados, e sobretudo reduzir as imperfeições da união aduaneira do Mercosul. Já para a Argentina, a necessidade de aprofundamento, independentemente das negociações da Alca, implicava avançar para a integração dos mercados, passando, de imediato, a enfrentar temas como os serviços, as compras governamentais e as políticas de concorrência, que haviam sido até então postergados no Mercosul, mas já se encontravam incorporados ao processo negociador hemisférico. Ao mesmo tempo, o governo argentino apresentou diversas propostas, em 1997, a fim de que a integração avançasse em campos como o da adoção de uma política de defesa comum, uma cidadania comum, e até mesmo uma moeda única, com vista em fortalecer o Mercosul como espaço econômico e político consolidado. Por sua parte, entretanto, o governo brasileiro reiterava que, antes de avançar em novas áreas, o Mercosul deveria consolidar o que já havia sido acordado.

No segundo semestre de 1997, o Mercosul logrou obter o consenso entre seus membros para iniciar negociações em temas que constavam da agenda da Alca e não haviam ainda sido enfrentados na integração sub-regional. No entanto, se o processo negociador hemisférico forçou o Brasil a aceitar alguns avanços do Mercosul para além da área estritamente comercial, as perspectivas de aprofundamento da integração sub-regional permaneceram limitadas pela posição brasileira radicalmente contrária a toda e qualquer iniciativa com a finalidade de conferir alguma autoridade supranacional ao bloco.
Nesse sentido, embora a posição brasileira de resistência ao aprofundamento do Mercosul foi fundamentada primordialmente em determinantes de natureza econômica e em decisões que não competem exclusivamente à diplomacia, também foi explicitada a oposição absoluta da diplomacia brasileira a qualquer possibilidade de que o País venha a aceitar uma maior cessão de soberania em prol do fortalecimento interno do bloco. O Ministro Lampreia declarava que "o Brasil não tem razão nenhuma para abrir mão da sua soberania", argumentando que a idéia da delegação, a uma autoridade supranacional, da capacidade de representar, negociar e impor normas para os Estados-membros do Mercosul, seria "absolutamente inaceitável para o Congresso Nacional, para a opinião pública brasileira, para a imprensa brasileira" (Lampreia, 1999:304).

No início de 1999, a crise do Mercosul atingiu estágio crítico, exacerbada pela desvalorização do real ocorrida em janeiro. Contudo, a prevalência da estratégia de alargamento na América do Sul sobre a opção do aprofundamento da integração sub-regional foi ainda explicitada quando o Brasil rompeu o formato $4+4$ nas negociações entre o Mercosul e a Comunidade Andina para obter logo um acordo $4+1$ com esse grupo. Ao longo do ano de 1999, no entanto, na medida em que as negociações hemisféricas haviam concluído a fase de pré-negociação e avançaram para o início do processo de redação do acordo da Alca, a diplomacia brasileira voltou a enfatizar a importância do bloco sub-regional como núcleo das relações externas do País. Apesar das dificuldades nas relações com seus parceiros sub-regionais, os determinantes externos do compromisso do Brasil com o Mercosul voltavam a manifestar-se. No entanto, foi também mantida a prioridade conferida à expansão regional, que culminou na convocação da cúpula de presidentes da América do Sul, realizada em Brasília, em agosto de 2000, ao mesmo tempo em que o "relançamento" do Mercosul permaneceu limitado.

\section{CONJUNTURA RECENTE}

Com o intuito explícito de assumir a liderança da América do Sul, a diplomacia brasileira conferia grandes expectativas, em 2000, à concretização do compromisso que havia obtido do Chile com o objetivo de que ele formalizaria, em poucos meses, sua plena adesão ao Mercosul. Foi nesse contexto que, no final do ano, o anúncio da abertura de negociações bilaterais entre Estados Unidos e Chile 
reverteu abruptamente o êxito que a diplomacia brasileira pretendia alcançar no avanço de sua estratégia regional, com implicações diretas nos planos sub-regional e hemisférico. O redirecionamento do Chile incitou a Argentina a manifestar seu apoio à proposta de antecipar a conclusão das negociações da Alca de 2005 para 2003, explicitando seu interesse na integração hemisférica e inclusive em negociações bilaterais com os Estados Unidos, seguida também pelo Uruguai, reabrindo divergências significativas entre as posições dos membros do Mercosul. Com a desestruturação da unidade sub-regional, foi atingido o cerne da estratégia perseguida pelo Brasil ao longo da década de 90 para fortalecer seu poder de barganha nas negociações hemisféricas.

No discurso da diplomacia brasileira, o redirecionamento chileno gerou nova prevalência da prioridade conferida ao plano sub-regional, em detrimento do alargamento e da liderança na América do Sul. Antes de deixar o cargo, o ministro Lampreia declarou nunca ter acreditado plenamente na possibilidade de expansão do Mercosul, citando, como exemplo, a Colômbia, que tem $60 \%$ de seu comércio com os Estados Unidos e uma equação política e militar própria com aquele país. Nesse sentido, não seria razoável pensar em uma frente sul-americana para as negociações da Alca, devendo o Brasil fortalecer sua posição com base na atuação conjunta do Mercosul (Valor Econômico, 2001). Também no discurso de posse do ministro Celso Lafer, foi reafirmado que as negociações na OMC, na Alca e com a União Européia exigem o fortalecimento do Mercosul. No contexto da crise argentina, entretanto, o principal avanço da cúpula do bloco, realizada em junho, foi o de impedir que houvesse retrocessos. Ao mesmo tempo, nas relações externas do Mercosul, a desarticulação do bloco manifestou-se não apenas nos intuitos argentinos e uruguaios de aproximação com os Estados Unidos, mas também na inexistência de uma posição conjunta perante a oferta apresentada pela União Européia para dar início à liberalização comercial inter-regional. Em um contexto no qual se acentuaram as inter-relações entre esses diversos processos, a reconstrução dessas articulações constitui o desafio de curto prazo para a política externa brasileira - sob o risco do isolamento.

\section{NOTAS}

1. Este artigo sintetiza argumentos desenvolvidos na tese de doutorado de Mello (2000).
2. Uma interpretação alternativa para a opção pelo estabelecimento de uma união aduaneira sugere que, dando prioridade à abertura econômica, teria sido buscada uma estratégia de lock-in, que consiste em vincular as reformas liberalizantes a acordos internacionais, com vistas a impedir eventuais retrocessos. Ver Batista (1994). Essas duas interpretações não são excludentes. Ao contrário, podem ter incidido cada uma sobre a opção de diferentes setores do governo brasileiro pela meta de criar uma união aduaneira e não apenas de uma área de livre-comércio.

\section{REFERÊNCIAS BIBLIOGRÁFICAS}

ABREU, M. de P. O Brasil e a Alca: interesses e alternativas. Rio de Janeiro, Departamento de Economia da PUC-Rio, 1997, (Texto para Discussão, 371).

ALBUQUERQUE, J.A.G. "US and Brazil bilateral relations as a major obstacle to hemispheric integration". Trabalho apresentado na conferência Una Grán Familia?: hemispheric integration after the Santiago Summit. Ottawa, outubro de 1998, mimeo.

BATISTA, P.N. "O Mercosul e os interesses do Brasil". Estudos Avançados. São Paulo, IEA/USP, v.8, n.21, 1994.

BOUZAS, R. "Mercosur's external trade relations: dealing with a congested agenda". In: ROETT, R. (org.). Mercosur: regional integration, world markets. Boulder/Londres, Lynne Rienner, 1999.

LAFER, C. "Relações Brasil-Argentina: alcance e significado de uma parceria estratégica". Contexto Internacional. Rio de Janeiro, IRI/ PUC-Rio, v.19, n.2, jul.-dez. 1997.

LAMPREIA, L.F. Diplomacia brasileira. Rio de Janeiro, Lacerda, 1999.

LIMA, M.R.S. de. "Brazil's response to the new regionalism". In: MACE, G. e THÉRIEN, J.P. (orgs.). Foreign policy and regionalism in the Americas. Boulder/Londres, Lynne Rienner, 1996.

“Brazil's alternative vision". In: MACE, G. e BÉRANGER, L. (orgs.). The Americas in transition. Boulder/Londres, Lynne Rienner, 1999.

MACHADO, J.B.M. e VEIGA, P. da M. A Alca e a estratégia negociadora brasileira. Rio de Janeiro, Funcex, 1997 (Texto para Discussão, 127).

MAGALHÃES, F.S. Cúpula das Américas de 1994: papel negociador do Brasil, em busca de uma agenda hemisférica. Brasília, Instituto Rio Branco/Fundação Alexandre Gusmão/Centro de Estudos Estratégicos, 1999.

MELLO, F. de C. "O Mercosul e a Alca". In: ALBUQUERQUE, J.A.G. e OLIVEIRA, H.A. de (orgs.). Relações internacionais e sua construção jurídica: a Alca e os blocos internacionais. São Paulo, FTD, 1998.

Regionalismo e inserção internacional: continuidade e transformação da política externa brasileira nos anos 90 . Tese de Doutorado em Ciência Política. São Paulo, FFLCH/USP, 2000.

PEREIRA, L.V. "Toward the common market of the south: Mercosur's origins, evolution and challenges". In: ROETT, R. (org.). Mercosur: regional integration. World Markets. Boulder/Londres, Lynne Rienner, 1999.

PINHEIRO, L. "Relações hemisféricas e política regional: uma disputa Mercosul-EUA?" In: SENNES, R.U. (org.). Brasil e a politica internacional. Santiago, Flacso-Chile/Wilson Center/Idesp, 1998. 
VALOR ECONÔMICO. "A agenda diplomática depois de Lampreia". São Paulo, 12/01/2001.

VEIGA, P. da M. "Mercosul: a agenda de consolidação interna e os dilemas de ampliação". São Paulo em Perspectiva. São Paulo, Fundação Seade, v.9, n.1, jan.-mar. 1995.

"Brazil in Mercosur: reciprocal influence". In: ROETT, R. (org.). Mercosur: regional integration, world markets. Boulder/ Londres, Lynne Rienner, 1999.

VIGEVANI, T. e MARIANO, K.L.P. "A burocracia na integração regional (e no Mercosul: influência no processo decisório". Con- texto Internacional. Rio de Janeiro, IRI/PUC-Rio, v.19, n.2, jul.dez. 1997.

VIGEVANI, T. e VEIGA, J.P.C. "Mercosul e os interesses políticos e sociais". São Paulo em Perspectiva. São Paulo, Fundação Seade, v.5, n.3, jul.-set. 1991.

Flavia de Campos Mello: Professora do Departamento de Política da PUC-SP. 